\title{
A DIREÇÃO DE ARTE COMO FERRAMENTA DE DESCONSTRUÇÃO DE ESTEREÓTIPOS: A REPRESENTAÇÃO VISUAL DAS MULHERES NEGRAS NO SERIADO ANTÔNIA
}

\author{
Luiza Gama Drable Santos \\ Pontifícia Universidade Católica do Rio de Janeiro \\ Izdrable@gmail.com \\ Nilton Gamba Junior \\ Pontifícia Universidade Católica do Rio de Janeiro \\ gambajunior@gmail.com \\ Liliane Ruth Heynemann \\ Pontifícia Universidade Católica do Rio de Janeiro \\ Irheynemann@gmail.com
}

Resumo: Este artigo tem em vista delinear as formas de representação da mulher negra na teledramaturgia brasileira contemporânea, tendo como base a análise de recursos visuais para composição das personagens femininas negras no seriado Antônia (2006). Para isso, serão observados os aspectos centrais de composição da direção de arte (cenografia e figurino) que denotam a manutenção ou não de estereótipos identitários das mulheres negras na narrativa. O objetivo é, no âmbito da comunicação visual, desenvolver dispositivos de análise para a direção de arte do seriado, observando elementos da cultura e identidade negras, assim como fatores que revelam as relações de gênero. Trabalha-se aqui com uma metodologia de levantamento de referencial conceitual interdisciplinar para elaboração de dispositivos de análise visual baseada na semiologia de Pier Paolo Pasolini, utilizando também como base conceitual os estudos teóricos propostos por autores como Stuart Hall, Joel Zito Araújo e Andreas Huyssen.

Palavras-chave: direção de arte, televisão, mulher negra, identidade

Abstract: This work means to take a look at black women's forms of representation in contemporary brazilian television, analizing the visual aspects that compose feminine black characters on the television series Antônia. For that, we'll observe the mean aspects of the production design's composition (scenography and costume) which demonstrate the conservation or not of black women's identity stereotypes in the story. Thinking about visual communication, we intend to create parameters to analyze the aspects that compose the series' design observing brazilian black cultural and identity elements, as well as gender issues. We worked with a methodology of interdisciplinary conceptual references to elaborate visual analysis methods based on Pior Paolo Pasolini's semiology studies, 
also using as conceptual basis the theorical studies of authors like Stuart Hall, Joel Zito Araújo and Andreas Huyssen.

Keywords: production design, television, black woman, identity

\section{INTRODUÇÃO}

O objetivo deste artigo é investigar de que forma as mulheres negras são representadas na teledramaturgia brasileira, focando a análise nas características visuais de composição das personagens protagonistas. Como base para a análise, temos a organização de referencial conceitual que permita um estudo no âmbito da Comunicação Visual. Para isso, foi realizado um recorte de conteúdo que priorizou o seriado Antônia (2006), por trabalhar temáticas voltadas para o cotidiano de quatro mulheres da periferia de São Paulo. Realiza-se aqui o levantamento teórico interdisciplinar que subsidia uma semiologia da materialidade e que gera dispositivos de análise para os elementos comunicacionais da direção de arte no audiovisual. 0 objetivo principal dessa análise é dar visibilidade a diferentes abordagens da narrativa ao representar mulheres negras de forma híbrida - texto e imagem. Ou seja, analisar as características imagéticas de composição da personagem feminina negra (direção de arte - figurino e cenografia), sempre levando em consideração alguns aspectos sociais de construção das personagens (status social, relacionamento interpessoal, composição familiar) e os conteúdos textuais que acompanham a representação visual.

Para a conceituação da análise visual, trazemos a tona questões relativas a construção da identidade e representação na pós-modernidade, baseadas nos estudos de Stuart Hall; como também questões relativas a etinicidade e a construção da identidade da mulher negra na teledramaturgia brasileira. No âmbito da técnica de análise da obra, e ainda a própria concepção de signos linguísticos, na discussão proposta por Pasolini em seu estudo sobre a semiologia da realidade. Vamos, portanto, partir de uma postura crítica em relação às 'coisas', que são compreendidas como signos linguísticos de uma situação histórica e social. Como aponta Pasolini, "uma escolha estética é sempre uma escolha social." (PASOLINI, 1990, p. 148). Por isso, entendemos a análise visual como um processo de construção dialética de sentido, que tem por base a compreensão da imagem audiovisual como um elemento compositivo e resultante de condições sociais do indivíduo.

Pasolini propõe para a imagem na fotografia e no cinema uma semiologia da realidade, que, como o próprio termo indica, tem relações diretas com a área do Design. Pasolini revê proposições semiológicas alicerçadas na imagem técnica, para pensar o inverso, a própria realidade como produtora de signos. Assim, propõe um processo de análise particular para o audiovisual, ou mesmo para a fotografia, e a sua representação do real. É importante destacar que Pasolini desenvolve também o conceito de linguagem pedagógica das coisas para dizer que a relevância dessa semiologia é porque essas imagens na realidade social (cortes de cabelos, tipos de corporeidade, roupas, etnias, arquitetura, urbanismo, gestos ou movimentação corporal em conjunto) ensinam ao indivíduo seu lugar social. Para Pasolini, uma criança, antes mesmo do domínio da fala, já sabe identificar seu lugar social pelos 
códigos dessa linguagem material, por isso sua implicação política e sua relevância social.

Pasolini analisa que os signos produzidos por uma sociedade do consumo estão mais desenvolvidos na inter-relação entre objetos, imagens técnicas, tipologia corporal, espaço urbano do que em manifestos textuais, assim, precisam ser estudados com ferramentas que deem conta dessa complexidade de suportes de base visual. A contribuição para o estudo da direção de arte do audiovisual como um recorte e da representação figurativa, em um escopo mais amplo, diz respeito a essa dimensão indicial de técnicas de representação mais realistas.

O audiovisual ou a fotografia como técnica realista não se restringe a um estilo ou gênero de produção, Pasolini se preocupa em delinear uma potencialidade da linguagem e não os gêneros apresentados na obra. Para dar conta disso, o autor afirma que o cinema não é o filme. Entende o Cinema como a potencialidade de uma linguagem ligada, na sua ontologia, a uma técnica e que se mantém identificada com ela nos percursos de experimentação das obras. Já o filme, é descrito como a intervenção criativa que pode ratificar de forma mais ou menos acentuada o potencial da linguagem, assim, constituindo-se gêneros diversificados quanto a identificação com a representação realista. No entanto, independente do gênero ou estilo de uma obra (filme) o realismo da linguagem e a demanda por uma semiologia que dê conta dos seus signos complexos e plurais vai sempre existir no audiovisual (cinema).

No desafio específico dessa pesquisa, que tem como objeto a mulher negra, fica claro a importância de códigos como penteados, estilos de roupa ou tons de pele em um recorte social que parte exatamente da identificação de um signo visual.

A proposta é, então, a análise comunicacional da combinação de elementos diferenciados e integrados da materialidade objetual dentro da direção de arte. Essa análise, deve partir da compreensão dos fenômenos por isso trabalha-se aqui numa perspectiva interdisciplinar de análise, onde os estudos da teoria da representação e da linguagem se aliam ao estudo do design, em um viés da visualidade.

Antônia faz parte de uma leva de conteúdos produzidos pela TV Globo que tinham como objetivo tratar da temática das periferias urbanas brasileiras, protagonizados majoritariamente por pessoas negras; como por exemplo os seriados Cidade dos Homens (2002, 2003, 2004 e 2005) e Carandiru - Outras Histórias (2005). Não por acaso, a produção desse tipo de conteúdo audiovisual voltado para contextos de pobreza e violência urbana, ganhou fôlego com o longa-metragem Cidade de Deus (2002), que tratando a favela como lugar de produção de subjetividade, obteve um grande sucesso de público e de crítica. Os dois outros seriados citados acima, assim como Antônia, partiram de um filme para serem transformados em projeto televisivo, em uma parceira da TV Globo com a produtora $\mathrm{O} 2$ Filmes.

A série, que teve duas temporadas, foi pensada como uma continuação do longa-metragem homônimo, e conta a história de quatro amigas, negras e pobres, moradoras da periferia de São Paulo, que sonham em concretizar seu desejo de ter um grupo de rap reconhecido na região. O enredo da série, escrito por Jorge Furtado, se desdobra no universo da música como local de realização pessoal dessas mulheres. Interpretadas por cantoras de diferentes estilos que se descobriram atrizes, as quatro amigas são Preta (Negra Li), Barbarah (Leilah Moreno), Mayah (Quelynah) e Lena (Cindy Mendes). A primeira temporada foi exibida em cinco episódios, entre novembro 
e dezembro de 2006. A segunda temporada estreou em setembro de 2007, e também foi composta por cinco episódios.

\section{DESENVOLVIMENTO}

Como coloca Hall (2005), o processo de formação da identidade cultural na pós-modernidade passa por um movimento de fragmentação, onde o sujeito não possui mais uma identidade unificada e estável como na modernidade, o que se discute é uma composição da identidade cultural cada vez mais pulverizada e variável e um sujeito composto por várias identidades conflitantes e contraditórias. Por isso, a sociedade pós-moderna teria como característica essa multiplicidade de elementos e "posições do sujeito" (HALL, 2005, p.4) que se articulam conjuntamente, deixando sempre a estrutura da identidade em aberto. Ou seja, há a configuração de uma sociedade descentrada e continuamente deslocada em seus centros de controle. Há, portanto, um agenciamento constante pelo sujeito de suas paisagens sociais e culturais de gênero, raça, classe, sexualidade e nacionalidade.

Neste sentido, a formação de identidade para o sujeito está profundamente misturada ao processo de representação. Segundo Hall (2005), a identidade é formada e transformada no interior de um sistema de representação cultural. Só podemos compreender a noção de construção de identidade quando analisamos um conjunto de produção de sentidos, com os quais o sujeito pode se identificar ou não. Por isso mesmo, o sistema de representação cultural é essencial para manutenção da construção de identidade do sujeito. Neste escopo da construção identitária através de diversos elementos e discursos culturais, o conceito de raça ${ }^{1}$ aparece, portanto, como uma categoria discursiva que possui nas práticas sociais e nos sistemas de representação sua forma de expressão mais contundente na sociedade contemporânea.

Como observa Hall, este processo de fragmentação da identidade no sujeito pós-moderno está relacionada a uma noção de afrouxamento da identidade nacional, em benefício de identidades culturais locais e comunitárias. Com isso, neste processo de pulverização cultural, produz-se um constante fluxo de "identidades partilhadas" (HALL, 2005), onde o local se une ao global através do crescimento do mercado global de consumo e de sistemas de comunicação mundialmente interligados. Assim sendo, os meios de comunicação midiáticos, como a televisão, se definem como relevantes maneiras de agenciamento das identidades culturais na contemporaneidade, em um processo de desvinculação das identidades a tempos, espaços e histórias específicas para se tornarem identidades cada vez mais fluidas e cambiantes.

Desta forma, o conceito de representação na cultura midiática da televisão é primordial para criar parâmetros para analisar de que maneira essas identidades fluidas pós-modernos, de que falamos, são compostas e recompostas na sociedade contemporânea.

Hall (2003) aponta ainda para o conceito de representação enquanto mediada por um sistema de produção de significados, através de uma linguagem na sociedade, indo ao encontro da análise semiológica de Pasolini. Esta linguagem sempre possui um

\footnotetext{
${ }^{1}$ Em vista do aporte teórico apresentado neste artigo, utilizaremos o conceito de "raça" no viés cultural, e não com uma conotação biológica.
} 
discurso específico provindo do emissor da mensagem. E apesar desta linguagem e seus códigos discursivos por vezes parecerem naturalmente dados, estes passam por um processo de construção da mensagem, que é produzida por um emissor com um sentido próprio. Por isso, a realidade é continuamente mediada através e pela linguagem, na construção de sentidos para os elementos constitutivos do mapa social por isso, a ideia de uma pedagogia das coisas. A representação faz parte da vida em sociedade do sujeito e se constitui como uma forma de conferir significado ao mundo e compartilhá-lo com o outro, levando-nos a pertencer a uma cultura. Logo, o conteúdo e a linguagem televisiva produzem significados atrelados a uma mensagem, que se constitui por uma combinação de dois tipos de discurso, o visual e o auditivo; de forma que se estabelece como um signo icônico, já que carrega em si características da coisa representada. Esse 'carregar' é a dimensão indicial que comentamos na semiologia de Pasolini. Pasolini reafirma e expande a análise de Barthes de que o cinema é uma linguagem metonímica, respondendo que a realidade também é (metonímica). Aqui Pasolini refirma as considerações Hall para uma realidade mediada pela linguagem - por conta disso, a própria realidade já é indicial e, portanto, metonímica. Metonímica por não dar conta de fato de uma realidade absoluta já que é sempre - mesmo que sem intermediação direta de veículos de comunicação - uma representação de partes editadas. Pasolini vai entender essa realidade com um fluxo de signos integrados que dá conta dessa hibridação no ato da percepção. Por conta disso, não podemos esquecer que o naturalismo no estilo de representação, na linguagem associada a uma técnica e nos elementos selecionados para a representação é sempre resultado de uma articulação específica da linguagem sobre o real, assim como a sua própria percepção não mediada (HALL, 2003).

A mídia cumpre funções sociais, como a integração social dos indivíduos e a reprodução cultural (ESTEVES, 1999), o que nos remete a sua capacidade de produzir representações de identidades estereotipadas e codificadas na sociedade contemporânea, nos mais diversos conteúdos midiáticos. Dessa forma, o rádio e televisão tiveram um papel decisivo no desenvolvimento dos relatos hegemônicos da cultural nacional na primeira metade do século XX.

Como aponta Arlindo Machado (2000), a televisão é um dos fenômenos culturais mais importantes do nosso tempo, entretanto há um preconceito acadêmico com o estudo dessa cultura massificada, pela suposta banalização do conteúdo em sua produção. Porém, o que o autor coloca é que essa banalização ocorre em qualquer esfera cultural que se proponha a realizar uma apropriação industrial da cultura; e seja na literatura ou no cinema, podemos encontrar esse tipo de abordagem mais mercadológica. Na contra mão dessa tendência, ao nos debruçarmos sobre a linguagem televisiva, como em outras linguagens (literatura e cinema), também encontramos uma produção de conteúdo mais denso e amplo, onde se propõe discutir os anseios da vida contemporânea.

Daí a importância, segundo Machado, de analisar a televisão como um dispositivo audiovisual e um meio de comunicação promissor por um lado, já que opera numa larga escala de audiência e alcança um grande público, o que possibilita a expansão de suas possibilidades expressivas. Por outro lado, não podemos esquecer que a televisão, e seus gêneros, opera sempre vinculada a um discurso ideológico, por isso não é um espaço de narrativa do real e sim de construção da realidade. E por isso, 
este projeto de construção do real está vinculado a um processo de homogeinização das referências coletivas (KELLNER, 2001).

Huyssen (1996) observa que a presença da mulher na cultura contemporânea, alavancada pelos movimentos artísticos e sociais emergentes nos anos 60 , tem como característica a posição diferenciada que este grupo social ocupa na sociedade em relação ao período do alto modernismo e das vanguardas históricas. O processo de desenvolvimento da pós-modernidade, como aponta Huyssen, possui como contraponto a noção de que o modernismo definia uma grande barreira entre a alta cultura e a cultura de massa; o que para a cultura contemporânea têm cada vez menos sentido. Processos culturais como o advento da Pop Art no início dos anos 60 borram cada vez mais essas fronteiras entre a alta arte e a cultura de massa, suprimindo a ideia de uma divisão entre estético e não-estético e retratando a cultura de massa em todas suas esferas de ação.

Dessa forma, o contexto histórico de desenvolvimento de movimentos sociais relacionados a questões de gênero e sexualidade, como o feminismo, foram terreno fértil para expansão da presença feminina na cultura contemporânea. Segundo Huyssen,

o ressurgimento da preocupação com a percepção e identificação, com a experiência sensual e com a subjetividade em relação ao gênero e a sexualidade dificilmente teria ganho destaque (indo contra até o poderoso argumento pósestruturalista da morte do sujeito e da apropriação derridaziana do feminino) se não fosse pela presença social e política do movimento das mulheres (...). (HUYSSEN, 1996, p.64)

O que quer dizer que a própria presença das mulheres na produção artística contemporânea fez mudar o status de leitura desta produção, pelas diferentes propostas de articulação das mulheres artistas enquanto sujeitos e produtoras de identidade, fazendo com que as velhas estruturas patriarcais e machistas da arte venham se tornando obsoletas. Entretanto, não podemos deixar de ressaltar que é claro que em relação a certas formas de cultura de massa, como por exemplo aquelas existentes nos padrões da televisão ou da indústria cinematográfica e publicitária, tão criticadas pelo movimento feminista, ainda persistem formas arcaicas de sexismo; e são as próprias mulheres que sofrem mais com os efeitos dessa cultura.

Sendo assim, o que pretendemos com o presente artigo é possivelmente delinear de que forma a representação da mulher negra na teledramaturgia brasileira se apresenta, sem esgotar as possibilidades de interpretação desses fenômenos, e entendendo que o conteúdo televisivo que será analisado pertence a um tipo de conteúdo diferenciado na televisão brasileira, o seriado. Podemos observar na síntese deste gênero um diálogo entre linguagem cinematográfica e linguagem televisiva, que se caracteriza, pelo menos na produção audiovisual brasileira, por uma maior experimentação linguística.

\subsection{Antônia e o processo de formação de identidade pelo viés da visualidade}

O seriado conta a história de resistência dessas quatro personagens negras e pobres da periferia a situações de desafios coletivos e pessoais. Permeado por uma constante reafirmação do lugar de fala da mulher negra, o espectador é progressivamente relembrado das raízes identitárias das personagens. 
A semiologia de Pasolini propõe um método para dar conta da desnaturalização crítica dessa realidade: o confronto entre os diversos recortes indiciais da metonímia. Para tanto, ele propõem o confronto das variáveis de observação. Se estiver analisando um período histórico, confronte com a mesma representação em outro contexto; se estiver analisando a representação em um suporte, coloque em diálogo com a mesma representação em outra mídia; se for a observação de um conteúdo em uma obra, observe o tratamento dado a outros conteúdos na mesma; ou, ao identificar as representações visuais, ver paralelamente as representações textuais. Aqui, aplicaremos especificamente o último recurso, trazendo à analise recursos textuais como letras de músicas e elementos visuais como figurinos - embora, a pesquisa como um todo, desenvolverá outras variáveis propostas por Pasolini.

Já na abertura do primeiro episódio do seriado ouvimos as vozes femininas que são protagonistas do enredo, cantando a música tema Antônia Brilha. Esta primeira música já dá indícios da forma como a história vai se desenrolar, ressaltando o lugar de destaque que a cultura do hip hop ocupa na construção narrativa. A música tema narra os percalços de ser mulher, pobre e negra; e ter que lutar e resistir pra seguir um sonho de cantar e ser reconhecida, como indica o seguinte trecho:

Vem ser mulher, vem conquistar o teu lugar

Um mundo novo onde ficar

Pra ser do bem, amar sem olhar a quem

É só querer barbarizar. Então, vem!

Orgulho é batalhar pra viver

Cantar é minha arma pra vencer

Nada pode parar!

Ninguém vai me calar!

Apenas pela escolha do universo retratado pela série já é possível perceber um esforço de seus criadores em discutir sobre conteúdos e personagens menos abordados pela teledramaturgia brasileira. Como aponta Araújo (2006), ao analisarmos a trajetória da representação das personagens negras na telenovela brasileira podemos encontrar uma grande homogeinizição da representação do negro na narrativa, constantemente relegado a papéis estereotipados em posições subalternas na sociedade representada. A discriminação que acontece neste espaço é nivelada conforme os traços de negritude e mestiçagem que apresentam os atores e as atrizes. Quanto mais traços não-brancos o artista apresenta, mais será relegado a papéis secundários e/ou estereotipados na trama. Conforme articula Araújo,

Todos eles, portanto, são obrigados a incorporar na televisão a humilhação social que sofrem os mestiços em uma sociedade norteada pela ideologia do branqueamento, em que a acentuação de traços negros ou indígenas significa a possibilidade de viver um eterno sentimento racial de inferioridade, e uma consciência difusa e contraditória de ser uma casta inferior que deve aceitar os lugares subalternos intermediários do mundo social. (ARAÚJO, 2006, p.77)

Neste caso, a direção de arte é um ponto central da discussão da desconstrução de estereótipos da narrativa. Porque é na composição espacial da cenografia e na construção visual do figurino da série onde se percebe grande parte 
das inovações linguísticas, no sentido de repensar as antigas formas de representação das mulheres negras, pelo viés da visualidade. Pelo menos no que tange a uma linguagem televisiva voltada para uma parcela populacional (mulheres negras) sempre tão negligenciada em suas representações.

A direção de arte é a área responsável pelo aspecto visual da obra. O diretor de arte é encarregado por criar junto ao diretor e ao fotógrafo uma atmosfera ${ }^{2}$ na qual o espectador será lançado pela história. Há um conjunto de elementos que compõe o design visual de um filme, determinados por seu contexto histórico, social, político, estético e imagético. A partir deste trabalho de contextualização que será realizado com base no roteiro e nas intenções do diretor com o projeto, o diretor de arte irá harmonizar elementos como a cenografia, o figurino, a maquiagem e os efeitos especiais, criando um desenho de produção. Isso significa que seu trabalho consiste na organização do espaço da encenação, no qual composição de cor, texturas e ambientação interajam e produzam um estilo singular.

Nos Estados Unidos o título de mais alto escalão da equipe de arte é de production designer, o que equivale ao diretor de arte nos projetos audiovisuais brasileiros - denominação que pode não deixar tão claro a associação à área do Design, como no termo norte americano. A definição de production designer, segundo Vincent LoBrutto (2002), é de que ele concebe toda a visualidade da imagem fílmica, sendo não só responsável pela criação dos cenários e coordenando equipes de figurinistas, maquiadores, cenotécnicos e contra-regras. Ele é responsável, portanto, pela criação de uma paleta de cores, a definição de detalhes periódicos e arquitetônicos relacionados ao roteiro, a seleção de locações em função disto e de outras questões, como o desenho e decoração de set, por isso, a contribuição direta do método projetual e da referência à comunicação visual.

Em relação a cenografia, a maior parte do seriado é gravado em locação. O que quer dizer que há um desejo por representar o espaço como ele é, ou ainda, preservar a legitimidade do local real. Há em toda composição visual da série essa vontade de se aproximar da realidade. Por isso, há o uso recorrente de uma linguagem na fotografia que se aproxima da câmera documental, por exemplo no uso constante de câmera na mão. Esta linguagem traz uma forma de olhar para a espacialidade que está ligada a própria percepção daquele espaço cênico como real. A importância de Brasilândia para a narrativa corrobora para uma construção espacial deste tipo.

O seriado Antônia, de certa forma, tenta quebrar com este estigma das mulheres negras na teledramaturgia nacional de representarem sempre personagens subalternas (escravas, empregadas domésticas, mulheres em situação de assédio moral e sexual, etc.). A voz narrativa que guia os dois primeiros episódios da primeira temporada do seriado é a da personagem Preta, interpretada pela cantora de rap e compositora Negra Li. Preta é uma mulher jovem, mãe solteira que vive com a filha, a mãe (interpretada pela cantora Sandra de Sá) e o pai na periferia de São Paulo, no bairro Vila Brasilândia. Os conflitos da personagem giram em torno de sua posição enquanto mulher em vários níveis de interação social na sociedade, ainda

\footnotetext{
${ }^{2}$ Trabalha-se aqui com a definição de atmosfera que é apresentada nos estudos de Inês Gil, cuja característica é dialogar com o espaço, que é "composto por forças visíveis e invisíveis, que têm o poder de desencadear sensações e afetos nos receptores".
} 
extremamente patriarcal e machista. No nível familiar, convive de maneira conturbada com o pai de Emília, Hermano (Fernando Macário), que não colabora em nada na criação da filha. No emprego como frentista, Preta é constantemente subjugada por seu chefe, que age com abuso de sua posição privilegiada enquanto homem e chefe. Ainda assim, mesmo com esses conflitos, a narrativa abre espaço para a personagem como protagonista de suas próprias ações, lutando por suas conquistas artísticas junto das três amigas.

Em vista disso, os conceitos de identidade e representação, como trabalhados nos estudos de Hall, são essenciais para identificar o lugar da etnicidade na construção imagética das mulheres negras na contemporaneidade. São esses agenciamentos de aspectos de formação da identidade que vão impulsionar a resistência à padrões midiáticos dominantes, dando espaço a discursos menos hegemônicos e mais centrados na diversidade. Esta heterogeneidade do discurso abre o universo da representação para comunidades negligenciadas, colocando-as em um local de centralidade na narrativa.

Antônia apresenta, assim, um discurso que prioriza mais a relação dessas mulheres com suas próprias imagens no processo de formação de suas identidades, em detrimento de uma visão estereotipada desses corpos. A relação com a etnicidade e a estética negra está na própria construção de uma imagem negra que resiste, na exploração de aspectos culturais de identificação desta população no Brasil.

A música, como parte integrante do enredo, dá essa possibilidade de escape do óbvio na construção narrativa. Como uma forma de reafirmação da identidade afro das quatro amigas, o hip hop e o rap perpassam os momentos de conflito para revelar a força das personagens e expressar a reação das mesmas ao contexto em que foram colocadas. O hip hop é reconhecido um movimento cultural reconhecido por congregar três pilares: a dança de rua, o rap (estilo musical) e o grafite (arte urbana). Segundo Guimarães (1998), o rap, assim como o samba e a música afro-baiana, é produzido pela população negra e mestiça, mas possui sua força na descrição da realidade de forma menos idealizada, produzindo um discurso mais direto, onde se difere do samba. Por isso, esta manifestação cultural tem força no diálogo com os problemas reais enfrentados pela população que a produz. Neste sentido, Antônia se aproxima dessa abordagem se utilizando da cultura negra, calcada na relação dessas quatro mulheres com os conflitos sociais que as atingem.

Em músicas como "Brasilândia", em que elas expõem os problemas sociais da periferia, podemos observar a necessidade de enfrentar o cenário social a que são impostas por meio da ação coletiva feminina, como notamos no trecho:

Liberdade, igualdade: minha necessidade

Estou de volta Brasilândia, minha verdade

Ganhar a rua: minha luta continua

Faço minha correria e se der tempo corro pela sua

Entre grades e concreto

Numa grande confusão

Uma intenção

"pá" na malandragem

Resolva a situação

Varias minas e um sonho

Quer desafiar? 
Demorou

Somos quatro

Neste sentido, há um apelo visual que está ligado a condição da mulher negra como voz ativa do processo de construção de subjetividade, e não como objeto do processo. Por isso, trabalha-se no figurino das personagens um maior uso de vestimentas que corroboram para a desnaturalização do corpo feminino como sexualizado. As vestimentas, em geral, pertencem ao universo do hip hop, onde as personagens exercem suas potencialidades artísticas. Nesta perspectiva, há o uso recorrente de calças jeans, roupas largas - o que facilita os movimentos da dança - tons escuros de preto e azul: todo um estilo de vestimenta que tem a rua como inspiração. A narrativa encontra seu fôlego visual justamente nos aspectos culturais de resistência da população negra, como a cultura hip hop e o rap. É nestes locais de disputa de território cultural onde as personagens expressam de forma contundente seus discursos de enfrentamento. Logo, o uso da vestimenta que pertence a este universo do hip hop - que tem sua origem em movimentos culturais da população negra nos anos 70 nos EUA - representa um dos alicerces da desconstrução de estereótipos para as personagens femininas dentro da narrativa.

De certa forma, a imagem não estereotipada das personagens também está presente no próprio trabalho de caracterização. Apesar de existir uma variação de corte de cabelo entre elas, algumas (como a personagem principal Preta e sua filha) utilizam um estilo de cabelo próprio da cultura negra. O cabelo crespo hoje é uma das maiores formas de resistência da estética negra, carregando consigo vários aspectos de emponderamento para as mulheres. Por se tratar de um desvio do padrão de beleza da sociedade, a estética negra (reforçada por aspectos como o cabelo crespo, o uso de turbante e tranças afro) reitera características essenciais para desconstrução de um estereótipo imagético eurocentrado.

\section{CONCLUSÃO}

A narrativa visual é composta pela aproximação das temáticas da mulher, da etnia e das mazelas sociais de se viver na periferia de São Paulo. De forma contundente, a série trabalha essa relação entre os clichês de representação da mulher negra e uma outra possibilidade de representação dessas mulheres.

Entretanto, por mais que observemos esse desejo de representar uma comunidade pelos próprios atores sociais pertencentes a ela na realidade, ainda existe na composição da produção estudada aqui um certo nível de elitismo e eurocentrismo recorrente da mídia dominante. Ou seja, quem produz essa história? Quem são os criadores do roteiro dessas histórias? Quem tem o poder discursivo para falar? Ao analisarmos os criadores e produtores da série Antônia, encontramos diretores já consagrados do audiovisual brasileiro, como Guel Arraes e Jorge Furtado, o que talvez legitimaria a produção da série dentro de uma emissora como a Rede Globo. Dificilmente, veríamos uma produção de tal porte sendo produzida somente por mulheres, e muito menos somente por mulheres negras.

Apesar disso, é importante ressaltar que a diretora do longa-metragem que deu origem a série, Tata Amaral, enxerga a importância de ter diversas mulheres compondo o corpo de direção da série na segunda temporada para construção de diferentes pontos de vista sobre as temáticas abordadas. Este debate suscita a 
necessidade de mudança também nas estruturas narrativas e métodos audiovisuais de produção, e não só na representação dos rostos em si. À caráter de comparação e a análise, sobre a atual situação da produção hollywoodiana Shohat e Stam observam que

afro-americanos, índios e latinos conquistaram o direito de "representar" suas próprias comunidades. Mas essas escolhas "realistas" não são suficientes se a estrutura narrativa e as estratégias cinematográficas permanecem eurocêntricas. Um rosto epidermicamente correto não garante a representação de uma comunidade. (SHOHAT; STAM, 2006, p.280)

Neste sentido, há um um esforço por parte dos criadores da série de representar esses grupos "minoritários" de forma mais próxima à realidade dos mesmos. E mais do que isso, como apontam Shohat e Stam, mais do que a necessidade de representá-los de forma realista, é necessário observar a abordagem discursiva que se compõe através da construção narrativa. Para quem e de que forma eles falam? Que discurso a série está produzindo para além da 'verdade representativa'? Sobre isso os autores propõe que podemos compreender a arte como "uma representação não tanto em um sentido mimético, mas político, uma delegação de vozes." (SHOHAT; STAM, 2006, p.265) Por este ângulo, verifica-se uma real intenção dos criadores e diretores da série de instituir um debate social e político sobre a posição que essas mulheres (negras, pobres e moradoras da periferia) ocupam na sociedade, bem como seus conflitos de classe, gênero e raça, em uma abordagem interseccional do problema.

A representação dentro dessa esfera social se apresenta, portanto, como um importante meio de visibilizar um conjunto de questões problemáticas de grupos que não possuem o poder de fala na mídia e nem o controle sobre sua própria representação. Segundo o que analisam Shohat e Stam, "nos campos de batalha simbólicos dos meios de comunicação de massas, a luta por representação tem correspondência política." (SHOHAT; STAM, 2006, p.268). Por isso a importância de se estudar dentro do ambiente elitista da academia temáticas como essa, que trazem para o debate formal questões relacionadas a diversas esferas sociais e políticas da nossa sociedade.

A visão positiva tanto no âmbito da linguagem textual, como na visual, que essas personagens representam desse grupo fazem com que elas se destaquem como membros ativos da comunidade a que pertencem, em um processo de reafirmação de características positivas desses grupos. De acordo com o que observam os autores, muitas vezes nos meios de comunicação de massa, a representação de membros de uma comunidade oprimida são generalizadas para toda comunidade, de forma que suas ações negativas acabam virando síntese de todo um grupo. Como colocam os autores,

as representações, portanto, se tornam alegóricas: no discurso hegemônico todo papel subalterno é visto como uma sinédoque que resume uma comunidade vasta, mas homogênea. Por outro lado, as representações dos grupos dominantes não são vistas como alegóricas, mas como "naturalmente" diversas, exemplos de uma variedade que não pode ser generalizada. (SHOHAT; STAM, 2006, p.269) 
Daí, a necessidade de se construir um discurso imagético que fuja das convenções narrativas dominantes e que proponha, neste sentido, uma divergência aos estereótipos comumente perpetuados pelos meios de comunicação de massa, apresentando uma visão positiva e vitoriosa desses grupos marginalizados.

Voltamos, então, a Pasolini e sua citação que nos lembra da importância psicossocial da pedagogia das coisas e de um enfrentamento politico das imagens signos no âmbito do design:

A Primeira imagem de minha vida é uma cortina, branca, transparente, que pende - imóvel, creio - de uma janela que dá para um beco bastante triste e escuro. Essa cortina me aterroriza e me angustia : não como alguma coisa ameaçadora e desagradável, mas como algo cósmico. (...) O que aquela cortina me disse e me ensinou não admitia (e não admite) réplicas. (PASOLINI,1990, p.126)

\section{REFERÊNCIAS}

ARAÚJO, Joel Zito. A negação do Brasil: O negro na telenovela brasileira. 2.ed. São Paulo: Senac, 2004.

ESTEVES, João Pissarra. Os media e a questão da identidade. Sob as leituras pósmodernas do fim do sujeito. Universidade de Lisboa, 1999. Disponível em: <www.bocc.ubi.p t>. Acesso em 15 de maio 2016.

HALL, Stuart. Da diáspora: identidades e mediações culturais . Belo Horizonte: Editora da UFMG, 2003.

2005.

A identidade Cultural na Pós-Modernidade. 10a ed. São Paulo: DP\&A,

HUYSSEN, Andreas. Memórias do modernismo. Rio de Janeiro: Editora UFRJ, 1996.

INÊS, Gil. A atmosfera como figura fílmica. In: Ciências da comunicação em congresso na Covilhã: III SOPCOM, VI LUSOCOM e II IBÉRICO, vol. 1, Estética e tecnologias da imagem, Covilhã, Universidade da Beira Interior, pp. 141-146.

KELLNER, Douglas. A cultura da mídia. Bauru, São Paulo: EDUSC, 2001.

LOBRUTTO, Vincent. The Filmmaker's Guide to Production Design. New York: Allworth Press, 2002.

MACHADO, Arlindo. A televisão levada a sério. SENAC Editora, São Paulo, 2000.

STAM, Robert; SHOHAT, Ella. "Estereotipo realismo e luta por representação". In: STAM, Robert; SHOHAT, Ella. Crítica da imagem eurocêntrica. São Paulo: Cosacnaify, 2006.

PASOLINI, Pier Paolo. Os jovens infelizes: antologia de ensaios corsários. São Paulo:

Editora Brasiliense S.A., 1990. 